\title{
Combined numerical and experimental determination of the convective heat transfer coefficient between an AICrN-coated Vanadis 4 tool and Rhenus oil
}

\author{
Üstünyagiz, Esmeray; Nielsen, Chris V.; Tiedje, Niels S.; Bay, Niels
}

Published in:

Measurement: Journal of the International Measurement Confederation

Link to article, DOI:

10.1016/j.measurement.2018.05.108

Publication date:

2018

Document Version

Peer reviewed version

Link back to DTU Orbit

Citation (APA):

Üstünyagiz, E., Nielsen, C. V., Tiedje, N. S., \& Bay, N. (2018). Combined numerical and experimental determination of the convective heat transfer coefficient between an AICrN-coated Vanadis 4 tool and Rhenus oil. Measurement: Journal of the International Measurement Confederation, 127, 565-570. https://doi.org/10.1016/j.measurement.2018.05.108

\section{General rights}

Copyright and moral rights for the publications made accessible in the public portal are retained by the authors and/or other copyright owners and it is a condition of accessing publications that users recognise and abide by the legal requirements associated with these rights.

- Users may download and print one copy of any publication from the public portal for the purpose of private study or research.

- You may not further distribute the material or use it for any profit-making activity or commercial gain

- You may freely distribute the URL identifying the publication in the public portal 


\section{Accepted Manuscript}

Combined numerical and experimental determination of the convective heat transfer coefficient between an AlCrN-coated Vanadis 4 tool and Rhenus oil

Esmeray Üstünyagiz, Chris V. Nielsen, Niels S. Tiedje, Niels Bay

PII:

S0263-2241(18)30498-6

DOI: https://doi.org/10.1016/j.measurement.2018.05.108

Reference: MEASUR 5609

To appear in:

Measurement

Received Date: $\quad 26$ July 2017

Revised Date: $\quad 19$ January 2018

Accepted Date: $\quad 27$ May 2018

Please cite this article as: E. Üstünyagiz, C.V. Nielsen, N.S. Tiedje, N. Bay, Combined numerical and experimental determination of the convective heat transfer coefficient between an AlCrN-coated Vanadis 4 tool and Rhenus oil, Measurement (2018), doi: https://doi.org/10.1016/j.measurement.2018.05.108

This is a PDF file of an unedited manuscript that has been accepted for publication. As a service to our customers we are providing this early version of the manuscript. The manuscript will undergo copyediting, typesetting, and review of the resulting proof before it is published in its final form. Please note that during the production process errors may be discovered which could affect the content, and all legal disclaimers that apply to the journal pertain. 


\title{
Combined numerical and experimental determination of the convective heat transfer coefficient between an AlCrN-coated Vanadis 4 tool and Rhenus oil
}

\author{
Esmeray Üstünyagiz $^{\mathrm{a},{ }^{*}}$, Chris V. Nielsen ${ }^{\mathrm{a}}$, Niels S. Tiedje ${ }^{\mathrm{a}}$ and Niels Bay ${ }^{\mathrm{a}}$ \\ ${ }^{a}$ Department of Mechanical Engineering, Technical University of Denmark, 2800 Kgs. Lyngby, Denmark
}

\begin{abstract}
Regardless of the field of application, the reliability of numerical simulations depends on correct description of boundary conditions. In thermal simulation, determination of heat transfer coefficients is important because it varies with material properties and process conditions. This paper shows a combined experimental and numerical analysis applied for determination of the heat transfer coefficient between an AlCrN-coated Vanadis 4 tool and Rhenus LA722086 oil in an unloaded condition, i.e. without the tool being in contact with a workpiece. It is found that the heat transfer coefficient in unloaded conditions at $80^{\circ} \mathrm{C}$ oil temperature is $0.1 \mathrm{~kW} /(\mathrm{m} 2 \cdot \mathrm{K})$ between the selected stamping tool and mineral oil. A sensitivity analysis of the numerical model was performed to verify the effects of mesh discretization, temperature measurement location and tool geometry. Among these parameters, mesh size and the thermocouple insert depth were identified as the critical parameters that affect the measured and calculated temperatures.
\end{abstract}

Keywords: Heat transfer, lubricant, numerical simulation, inverse analysis

\section{Introduction}

In metal forming about $90-95 \%$ of the mechanical energy used in the process is converted to heat ${ }^{1}$. Some of the heat remains in the deformed region and some flows into the undeformed material. The remaining heat flows into the tooling and to the environment ${ }^{2}$. The temperature distribution in a forming process depends on the following points:

- The initial temperature of each part.

- Heat generation due to plastic deformation and friction.

- Heat transfer between the parts.

- Heat transfer between the parts and/or the lubricant and the environment.

Heat transfer across the interfaces depends on the heat transfer coefficient (HTC). For determination of the HTC in unloaded condition, Semiatin et al. ${ }^{3}$ used two steel dies with different initial temperatures and brought them together under varying pressures. Burte et al. ${ }^{4}$ used ring tests with pre-heated dies to compress 304 stainless steel rings. Two thermocouples were embedded in the lower die with different distances to the die-workpiece interface. The ring compression test was then simulated and the temperature history of the two nodes having the same location as the actual thermocouples was stored. The experimental temperature history was then used to match the numerical results with various HTCs. These studies concluded that the HTC at the contact interface in the free resting condition, i.e. without being subjected to load, is about $1 \mathrm{~kW} /\left(\mathrm{m}^{2} \cdot \mathrm{K}\right)$. Inverse methods are commonly used by many researchers to

Corresponding author. Tel.: +45254728; fax: +45251960

E-mail address: esustu@mek.dtu.dk 
determine the HTC not only during loading but also in the unloaded condition. To give some examples, Geiger et al. ${ }^{5}$ proposed to use a cup deep drawing test for hot stamping of $22 \mathrm{MnB} 5 \mathrm{Al} / \mathrm{Si}$ coated ultra-high strength steel and they calculated the HTC as $0.1 \mathrm{~kW} /\left(\mathrm{m}^{2} \cdot \mathrm{K}\right)$. For aluminum alloy 2024-0 in an unloaded case, the HTC was however $1.5 \mathrm{~kW} /\left(\mathrm{m}^{2} \cdot \mathrm{K}\right)$ at $50^{\circ} \mathrm{C}$ (cf. Burte et al. ${ }^{4}$ ). For forging applications, Jain ${ }^{6}$ studied the effect of lubricants on the HTC and concluded that changes in HTC is closely related to the chemistry of the lubricant with varying temperatures. He also stated that the HTC is an order of magnitude lower in the unloaded condition. Bariani et al. ${ }^{7}$ analyzed the thermal conditions between tool and workpiece in hot forging. They determined the HTC as function of deformation and cooling phases during hot forging cycles. More recently, Asai et al. ${ }^{8}$ proposed a low-speed hot-ring compression test to identify the performance of the lubricants at elevated temperatures when considering the heat transfer between air-workpiece and die-workpiece. In an additional study they have implemented the HTC between lubricant-die and lubricant-workpiece ${ }^{9}$. The results showed that the friction coefficient was underestimated when heat transfer and the effect of velocity are not taken into account when producing calibration curves for the ring test by numerical simulation. In other words, lubricant heat transfer affects the metal forming process and should be taken into account. Determination of the range of HTC on the other hand is rather complicated and varies as a function of the tool material, workpiece material, lubricant properties and the process. It is therefore important to determine the value of the HTC for each specific process separately.

In numerical simulation of heat transfer in metal forming operations, a boundary is usually defined where the heat transfer occurs due to plastic deformation and heat generation. The HTC is usually adjusted to match the numerical results with experimental measurements in addition to other assumed parameters such as friction ${ }^{10}$. Those assumptions influence the accuracy and reliability of the numerical model. Additionally, the heat transfer between tooling and environment is either neglected or heat transfer directly between tool and the air is considered ${ }^{11}$ neglecting the influence of lubricant on the tool surface. This may give rise to large errors when analyzing a production process, where lubrication is provided by flushing over tools and workpieces. In this case, the lubricant will act as a coolant so the heat flux on free surfaces becomes an important boundary condition. Accurate definition of boundary conditions in finite element modelling is essential for the correct prediction of process parameters, so it is necessary to include the thermal effect of the lubricant in the process and thus to determine the HTC of specific lubricants.

The present work deals with determination of the HTC in relation to an industrial case, where a local tube protrusion in a sheet is created by simultaneous collar drawing and ironing. Fig. 1 shows the process schematically as the sheet starts with a pre-punched hole. The company Grundfos utilizes this to produce a stainless steel cap for a water pump, where a slide bearing is mounted inside the tube. The combined collar drawing and ironing is tribologically critical, and galling appears if insufficient lubrication is applied ${ }^{12}$. In the specific case, the HTC is determined between an AlCrN-coated powder metallurgy (PM) tool steel (Vanadis 4 from Uddeholm) and a mineral oil with additives (Rhenus LA722086) having a kinematic viscosity of $900 \mathrm{~mm}^{2} / \mathrm{s}$ at $40{ }^{\circ} \mathrm{C}$. The analysis is based on experimental measurement of the temperature development in the tool, when dipping it in a warm oil bath and an inverse analysis by numerical modelling. A sensitivity analysis was performed to estimate the effect of the mesh discretization, actual location of the temperature measurements and the importance of the punch geometry in the numerical simulations.

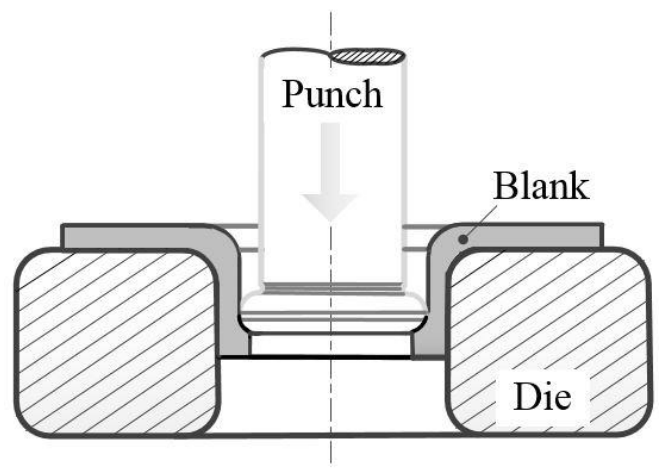

Fig. 1. Schematic of ironing process. 


\section{Methods and Procedure}

\subsection{Punch Design}

Fig. 2 shows the ironing punch used in the production process. During the forming operation, the workpiecepunch contact occurs along the punch nose, marked with the lower ellipse in Fig. 2a, and the aim was to measure the temperature as close as possible to the contact interface. Additionally, the design of thermocouple holes must ensure a way out of the tool and press for the electric wires, when the punch is mounted. Due to the geometrical restrictions, the only way to reach the punch nose is from the upper side. Using multiple measurement points located at various positions would contribute to the accuracy of the numerical model when comparing the numerical and experimental temperature values, especially during the ironing process where higher temperatures are obtained. On the other hand, the design must also ensure that the stiffness of the tool will not be affected by introducing additional holes. Two thermocouple holes were therefore selected and the diameter of the holes were kept as small as possible. The punch with its thermocouple holes is illustrated in Fig. 2a. The holes are $86.3 \mathrm{~mm}$ deep and placed with $4.2 \mathrm{~mm}$ distance from the bottom end of the punch. The diameter is $2.2 \mathrm{~mm}$, which is the same as the diameter used in the earlier work in the authors' group ${ }^{12}$. The distances from the center of the hole to the inner surface of the punch nose are $2.9 \mathrm{~mm}$ and $3.9 \mathrm{~mm}$. The flat bottom holes were machined by Electrical Discharge Machining (EDM).

a

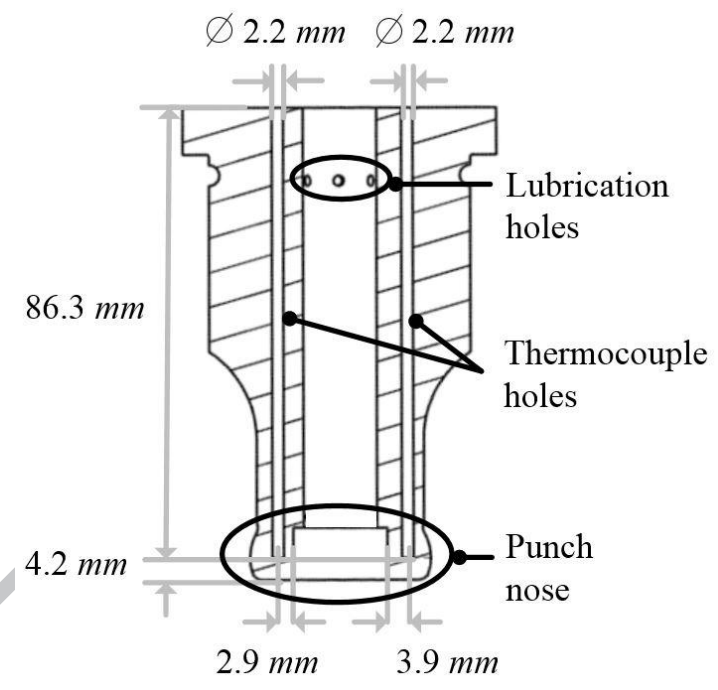

b)

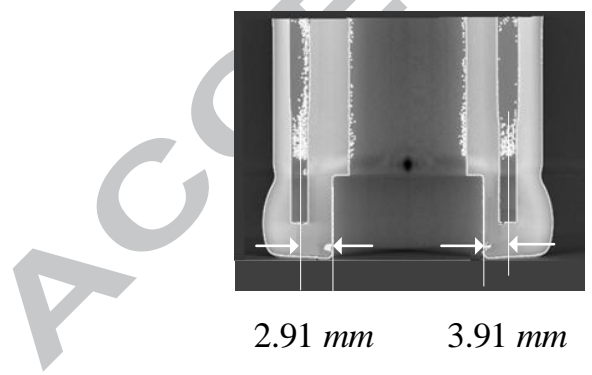

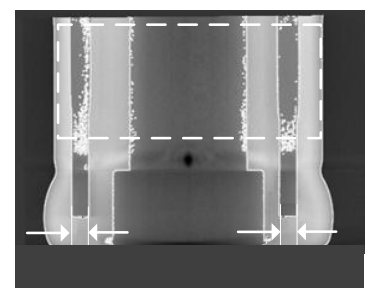

$2.17 \mathrm{~mm} \quad 2.17 \mathrm{~mm}$

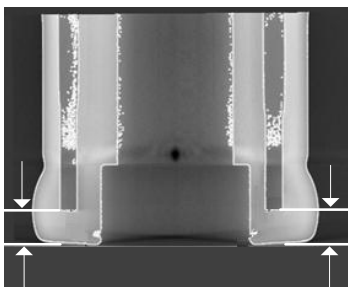

$4.11 \mathrm{~mm} \quad 4.18 \mathrm{~mm}$

Fig. 2. Punch with the details of thermocouple holes shown by a) a schematic illustration and b) computed tomography (CT) scanning images of the actual punch. 


\subsection{Thermocouple Selection and Mounting}

The flatness of the bottom of the hole is especially important for the thermocouple insert in order to define the exact temperature measurement location. However, it is difficult to ensure a flat bottom surface for deep holes. For identification of the actual geometry, Computed Tomography (CT) scanning was used. The punch was scanned using a Scanning XT H 225 ST Industrial CT machine. The CT scanning parameters used in this study are listed in Table 1.

In total 1500 images with a resolution of $43 \mu \mathrm{m}$ were obtained. VGStudio MAX software was used to construct a $3 \mathrm{D}$ volume set from the images. The critical dimensions are shown in Fig. $2 \mathrm{~b}$. The scanned dimensions suggested that the bottoms of the holes are flat and that the diameters are $2.17 \mathrm{~mm}$. For the calculation of the error, the diameter of the punch in the region identified by the dashed white rectangular in Fig. $2 \mathrm{~b}$ was measured and compared with the corresponding measurement by using a caliper. The accuracy of the measurement is calculated as $\pm 0.1 \mathrm{~mm}$. Based on this, the chosen diameter of the thermocouple is $2.0 \mathrm{~mm}$, which ensures sufficient space for mounting in the holes.

Among various thermocouple types, the T-type has the lowest standard error within the temperature range of $250{ }^{\circ} \mathrm{C}$ to $350{ }^{\circ} \mathrm{C}$, which covers the operation range of this study. Additionally, the grounded type of junction has the fastest response for non-fluid applications ${ }^{13}$. A T-type thermocouple with a grounded probe was therefore selected.

\begin{tabular}{lll}
\hline Parameter & & Value \\
\hline Current & {$[u A]$} & 741 \\
Filter material & & Copper \\
Filter thickness & {$[\mathrm{mm}]$} & 2.5 \\
Integration time & {$[\mathrm{s}]$} & 2 \\
Number of projections & & 1500 \\
Power & {$[\mathrm{W}]$} & 150.4 \\
Voltage & {$[\mathrm{kV}]$} & 203 \\
Voxel size & {$[\mu]$} & 43 \\
\hline
\end{tabular}

Table 1. CT scanning parameters.

\subsection{Experimental Set-up}

The experimental set-up used in this study is illustrated in Fig. 3 and the parameters used during the experimental investigations are given in Table 2. 


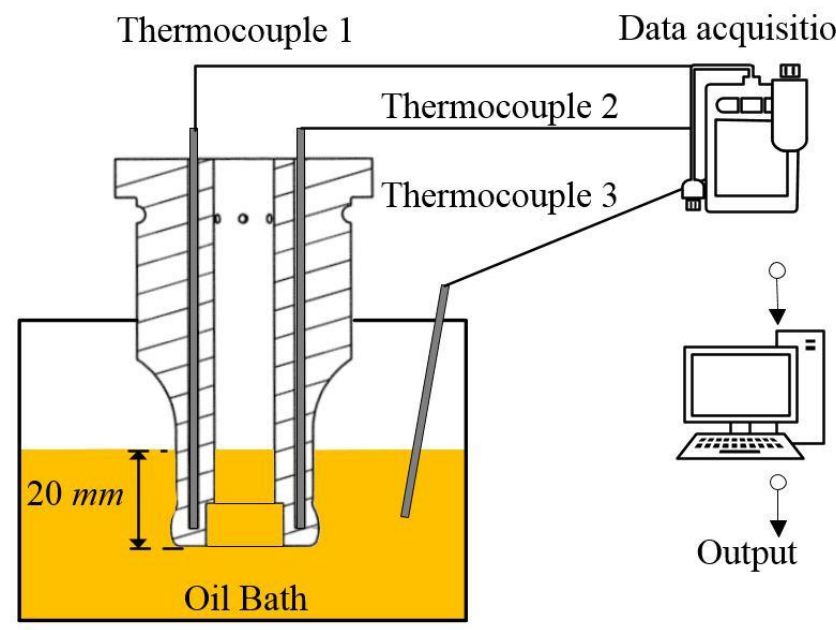

Fig. 3. Schematic of experimental set-up.

A container was filled with approximately $500 \mathrm{~mL}$ Rhenus oil and heated up to $80{ }^{\circ} \mathrm{C}$. The oil was heated and circulated by a hot plate stirrer to maintain a uniform temperature distribution. The two thermocouple tips were covered with thermally conducting paste and inserted in the holes. When the temperature of the oil was constant, the punch was dipped $20 \mathrm{~mm}$ into the bath as shown in the Fig. 3. The two measured temperatures in the punch and the oil temperature were each sampled with an acquisition rate of two per second. During the first experiment it was realized that the stirring plate stopped rotating which resulted in fluctuations in measured lubricant temperature. The test was repeated to ensure steady temperature value of the lubricant and the results were further used.

\begin{tabular}{lll}
\hline Parameter & Value \\
\hline Punch material & PM tool steel (Vanadis 4 from Uddeholm) AlCrN-coated \\
Initial punch temperature & {$\left[{ }^{\circ} \mathrm{C}\right]$} & 20 \\
Lubricant & & mineral oil with additives (Rhenus LA722086) \\
Lubricant temperature & {$\left[{ }^{\circ} \mathrm{C}\right]$} & 80 \\
Lubricant viscosity @ $40{ }^{\circ} \mathrm{C}\left[\mathrm{mm}^{2} / \mathrm{s}\right]$ & 900 \\
Lubricant volume & {$[\mathrm{mL}]$} & 500 \\
Thermocouple type & & A-type with grounded probe \\
\hline
\end{tabular}

Table 2. Experimental parameters.

\subsection{Numerical Model}

Fig. 4 shows the finite element mesh of the punch with dimensions given in Fig. 2a. The punch was discretized by approximately 260,000 tetrahedral elements and 51,000 nodal points. The elements subjected to heat transfer from the lubricant are highlighted in Fig. 4. For those elements, a convection boundary condition with the lubricant was defined. For rest of the punch, which was in contact with the air, convection as well as radiation boundary conditions were specified. 


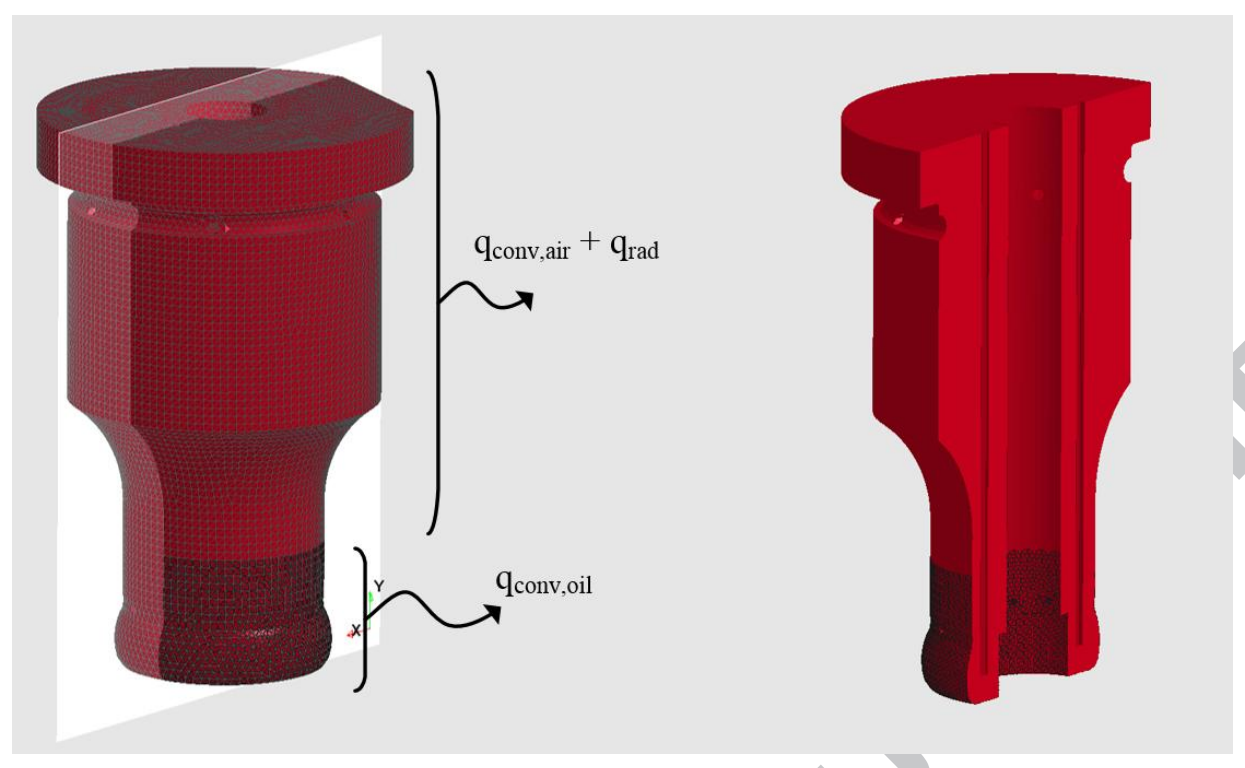

Fig. 4. Representation of three dimensional discretization of the punch for thermal modelling with cross-sectional detail and indication of convection and radiation boundary conditions.

The material properties used in the numerical model are presented in Table 3. The punch had an initial temperature of $20{ }^{\circ} \mathrm{C}$. The heating of the punch was achieved by fictitious lubricant contact by assigning a final temperature of $80^{\circ} \mathrm{C}$.

\begin{tabular}{lll}
\hline Parameter & & Value \\
\hline Structural density & {$\left[\mathrm{kg} / \mathrm{m}^{5}\right]$} & 7.600 \\
Thermal conductivity ${ }^{14}$ & {$\left[\mathrm{~W} / \mathrm{m} \cdot{ }^{\circ} \mathrm{C}\right]$} & 15 \\
Heat capacity ${ }^{14}$ & {$\left[\mathrm{~J} / \mathrm{kg} \cdot{ }^{\circ} \mathrm{C}\right]$} & 460 \\
Initial punch temperature & {$\left[{ }^{\circ} \mathrm{C}\right]$} & 20 \\
Air temperature & {$\left[{ }^{\circ} \mathrm{C}\right]$} & 20 \\
Lubricant temperature & {$\left[{ }^{\circ} \mathrm{C}\right]$} & 80 \\
Heat transfer coefficient with air ${ }^{15}$ & {$\left[\mathrm{~W} / \mathrm{m}^{2} \cdot \mathrm{C}\right]$} & 10 \\
Stefan-Boltzmann constant & {$\left[\mathrm{W} / \mathrm{m}^{2} \cdot \mathrm{C}^{4}\right]$} & $5.6703 \cdot 10^{-8}$ \\
\hline
\end{tabular}

Table 3. Input punch properties and process parameters used in numerical simulations.

\section{Results and Discussion}

\subsection{Determination of the heat transfer coefficient}

Fig. 5a illustrates the measured temperature during the experiment. There is no significant difference between the temperatures measured in the punch with Thermocouple $1\left(\mathrm{TC}_{1}\right)$ and Thermocouple $2\left(\mathrm{TC}_{2}\right)$. A preliminary numerical analysis was performed and the temperature evaluations for the nodes, where the $\mathrm{TC}_{1}$ and $\mathrm{TC}_{2}$ are situated, were obtained. The results are presented in Fig. 5b. Similar to the experimental results, the two temperature curves are very close to each other. For simplicity, only one thermocouple, $\mathrm{TC}_{2}$ was selected for use in the comparison with the results of the numerical analysis. 
A number of FEM simulations were carried out with different heat transfer coefficients; $h=80,100$ and 120 $W /\left(m^{2} \cdot K\right)$. In Fig. 5b, the numerically computed temperature history of the node taken from the $\mathrm{TC}_{2}$ location is compared with the experimental evolution of temperature. The results suggest that the best match between numerical and experimental results is obtained when the HTC is $h=100 \mathrm{~W} /\left(\mathrm{m}^{2} \cdot \mathrm{K}\right)$. The curves also show that the HTC is greater in the beginning of the experiment, whereas it converges to $h=100 \mathrm{~W} /\left(\mathrm{m}^{2} \cdot \mathrm{K}\right)$ after 40 seconds. The initial variation in HTC is a result of the boundary layer that is instilled around the punch as it immersed in the liquid. There is a transitional period where the boundary layer builds up and becomes stable giving a constant HTC. The aim of this study is to define a HTC value which is going to be used as a boundary condition in a steady state system. Therefore, the HTC value is determined after the temperature curves are stable.

a

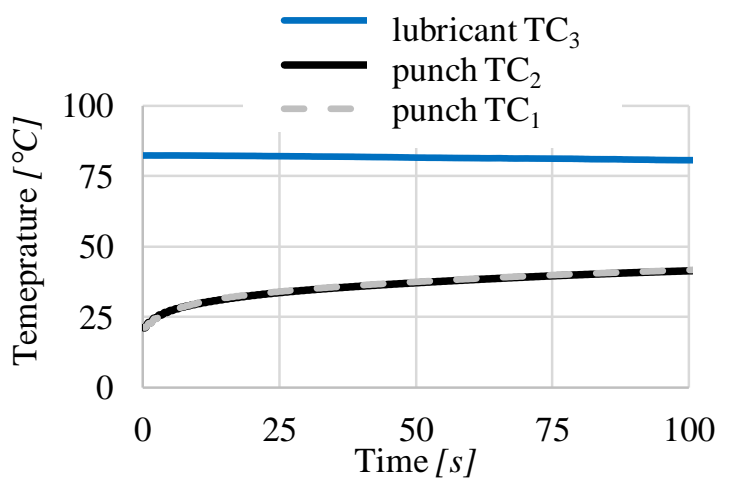

b

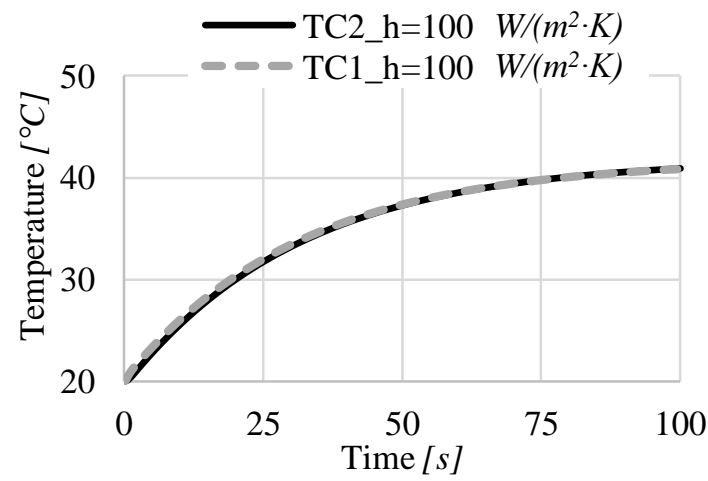

c

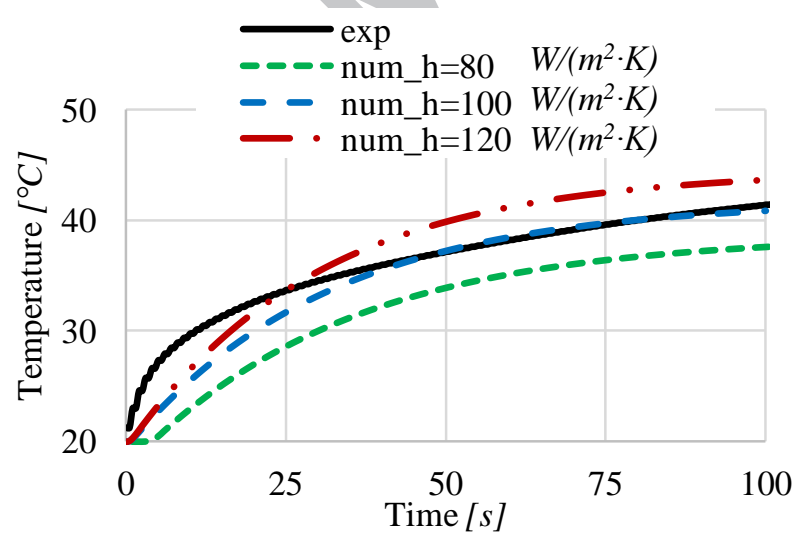

Fig. 5. Temperature evolution with time representing a) experimental results taken from thermocouples 1,2 and 3 ; b) numerical results taken from Thermocouple 1 and Thermocouple 2 positions for a specific heat transfer coefficient, $h=100 \mathrm{~W} /\left(\mathrm{m}^{2} \cdot \mathrm{K}\right)$; c) comparison of numerical results taken from Thermocouple position 2 using various heat transfer coefficient values with experimental findings.

\subsection{Sensitivity analysis on the finite element mesh discretization}

A number of numerical analyses were performed to determine the influence of finite element mesh discretization on the level of convergence. The current model uses approximately 260,000 tetrahedral elements and 51,000 nodal points. The mesh was regenerated by using a finer mesh with twice as many elements and a coarser mesh by using 
half as many elements as in the current model. The numerical simulation was run using the same parameters listed in Table 3. The temperature curves determined in the same TC2 node are given in Fig. 6.

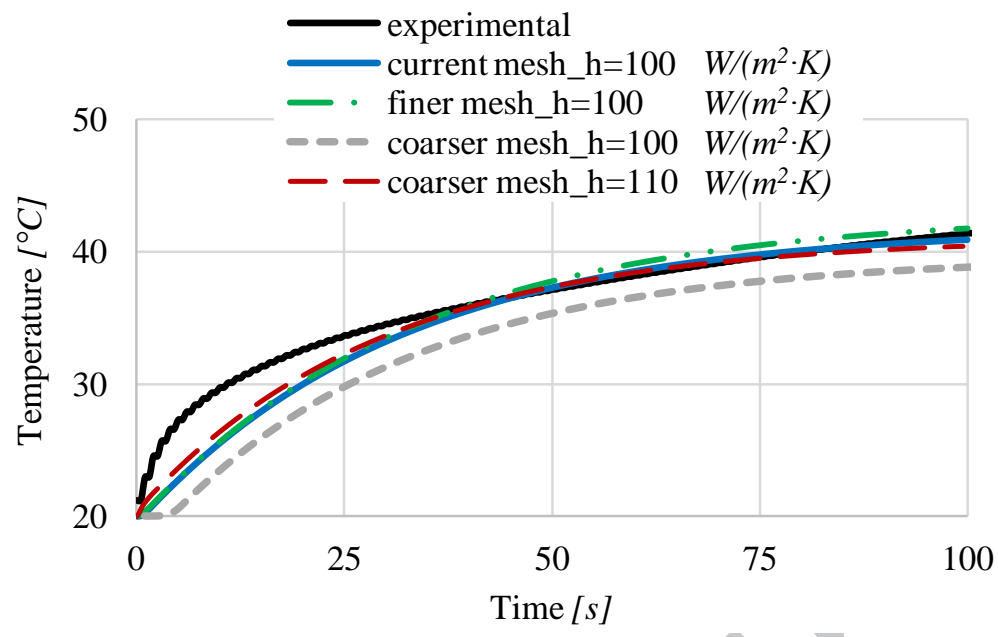

Fig. 6. Temperature evolution with time taken from Thermocouple position 2 using various discretizations of the punch.

The results indicate that using coarser mesh for determination of the HTC can be deceptive. Coarser mesh discretization yields a value of HTC of $h=110 \mathrm{~W} /\left(\mathrm{m}^{2} \cdot \mathrm{K}\right)$. However, when the punch was discretized to the current size, the HTC is found to be $h=100 \mathrm{~W} /\left(\mathrm{m}^{2} \cdot \mathrm{K}\right)$. When the mesh was further refined by a factor of two and the same HTC is used, similar temperature curves with both 'current mesh' and 'finer mesh' were obtained. The current simulation takes 2 minutes, whereas finer mesh increased the CPU time to 20 minutes. The current mesh size may thus be seen suitable for this study.

\subsection{Sensitivity analysis on the location of the measurement point}

A number of numerical analyses were performed to determine the sensitivity of the location of the thermocouple measurement point. Selected nodes are shown in Fig. 7a, and the corresponding temperature histories are given in Fig. $7 b$.

Ideally, the experimental set-up would be designed to measure the temperature on the flat bottom surface of the hole. The flatness of the bottom was verified by CT scanning. However, the exact position of the temperature measurement point, where the thermocouple junction touches the surface during the experiment, is unknown. The temperature history of the three different nodes, A, B and C, which are lying on the thermocouple contact surface (see Fig. 7a), were therefore calculated and compared with the experimental results. Fig. $7 \mathrm{~b}$ shows that the temperature evolutions of the three nodes $\mathrm{A}, \mathrm{B}$ and $\mathrm{C}$ are very close to each other. This may be due to the heat flow from both sides of the punch nose. However, the temperatures of the nodes, D and E, which are lying above the ideal thermocouple contact surface are lower. At a distance of $2.6 \mathrm{~mm}$ above the contact surface, the overall temperature decreases up to $1.5{ }^{\circ} \mathrm{C}(3.6 \%)$. 


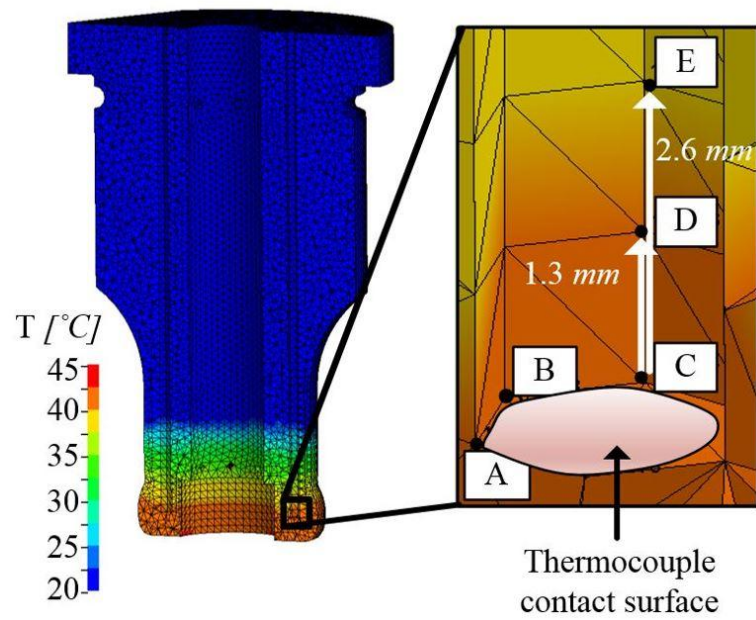

b

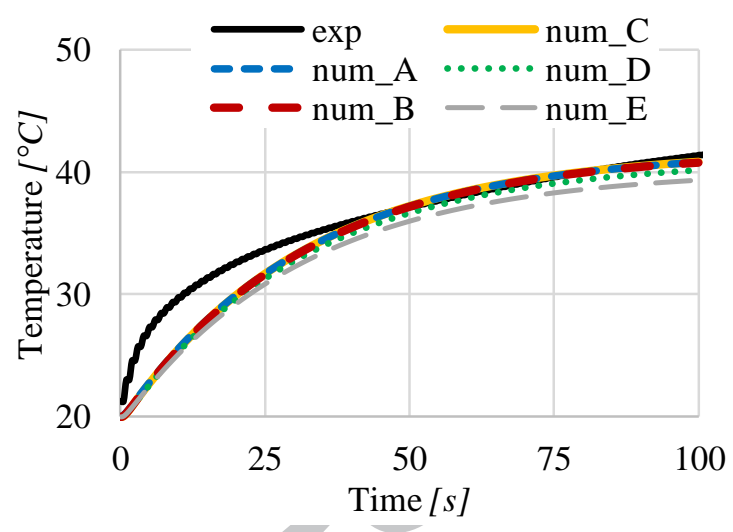

Fig. 7. Sensitivity analysis of measurement position shown by a) punch mesh and position of nodes and b) temperature evolution with time for the selected positions.

\subsection{Sensitivity analysis on the punch volume}

To assess the influence of the punch geometry in the numerical results, the $3 \mathrm{D}$ mesh of the punch was regenerated without thermocouple holes. A numerical simulation was run using the parameters listed in Table 3 and the HTC was kept at $100 \mathrm{~W} /\left(\mathrm{m}^{2} \cdot \mathrm{K}\right)$ as had been previously estimated. The temperature history was taken from the nodes with similar coordinates for the full mesh of the punch and for the model neglecting thermocouple holes. Fig. 8 illustrates the temperature evolution of the numerical results and the comparison with experimental findings. The results indicate that, for this specific heat flow condition, the modelling of thermocouple holes has no significant influence on the temperature prediction.

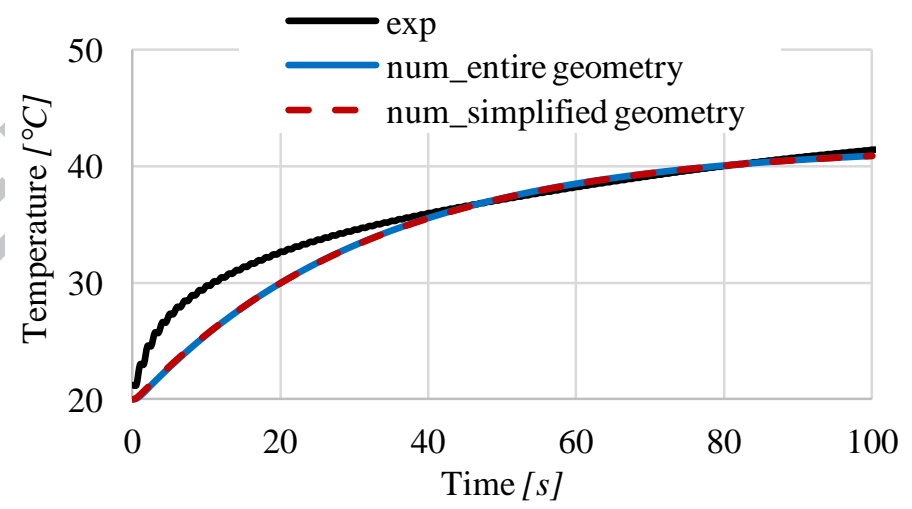

Fig. 8. Temperature evolution with time for two punch meshes and comparison with experimental results. 


\section{Conclusions}

In this study, combined experimental and numerical analysis is conducted to determine the heat transfer coefficient between an $\mathrm{AlCrN}$-coated PM tool steel and a mineral oil used for sheet stamping. An inverse analysis suggests that the heat transfer coefficient in unloaded conditions at $80{ }^{\circ} \mathrm{C}$ oil temperature is $0.1 \mathrm{~kW} /\left(\mathrm{m}^{2} \cdot \mathrm{K}\right)$.

A sensitivity analysis has been performed to reveal the influence of several parameters on the determination of HTC. The choice of the mesh size of the numerical model can be critical for the precise prediction of the HTC. Additionally, the results show that the vertical positioning of the thermocouple corresponding to the insert depth is more critical than the radial positioning. On the other hand, the influence of the thermocouple holes has shown no impact on the results.

Future work should include the thermo-mechanical analysis of a forming process involving the HTC found in this work as an initial boundary condition. However, it should be noted that the boundary, where the plastic deformation occurs, must be analyzed again to take the effect of pressure and temperature on the HTC into account; whereas, for the rest of the boundary, where no workpiece contact appears, the determined HTC can be utilized.

\section{Acknowledgements}

The authors wish to extend their sincere thanks to Mr. Ali Fallahiarezoodar, Dr. Alessandro Stolfi and Mr. Frederik W. Andersen. The work was supported by the Danish Council for Independent Research [grant no. DFF 4005-00130].

\section{References}

1. Farren, W. S. \& Taylor, G. I. The Heat Developed During Plastic Extension of Metals. in Proceedings of the Royal Society of London Series A-containing Papers of a Mathematical and Physical Character 422451 (1925).

2. Altan, T., Ngaile, G. \& Shen, G. Cold and Hot Forging, Chapter 6. (ASM International, 2005).

3. Semiatin, S. L., Collings, E. W., Wood, V. E. \& Altan, T. Determination of the Interface Heat Transfer Coefficient for Non-Isothermal Bulk-Forming Processes. J. Eng. Ind. 109, $49-57$ (1987).

4. Burte, P. R., Im, Y.-T., Altan, T. \& Semiatin, S. L. Measurment and Analysis of Heat Transfer and Friction During Hot forging. J. Eng. Ind. 112, 332-339 (1990).

5. Geiger, M., Merklein, M. \& Lechler, J. Determination of tribological conditions within hot stamping. Prod. Eng. 2, 269-276 (2008).

6. Jain, V. K. Determination of Heat Transfer Coefficient for Forging Applications. J. Mater. Shap. Technol 8, 193-202 (1990).

7. Bariani,P., Berti, G. \& Negro, T. D. Experimental evaluation and FE simulation of thermal conditions at tool surface during cooling and deformation phases in hot forging operations. CIRP Ann. 51, 219-222 (2002).

8. Asai, K. \& Kitamura, K. Estimation of frictional property of lubricants for hot forging of steel using lowspeed ring compression test. Procedia Eng. 81, 1970-1975 (2014).

9. Asai, K., Kitamura, K., Yukawa, N. \& Hayashi, N. Estimation of friction by using improved calibration curves of ring compression test for hot forging of steel. Procedia Eng. 207, 2280-2285 (2017).

10. Olsson, D. D., Bay, N. \& Andreasen, J. L. Prediction of limits of lubrication in strip reduction testing. CIRP Ann. - Manuf. Technol. 53, 231-234 (2004).

11. Altan, T. \& Tekkaya, A. E. Sheet metal forming - Processes and Applications. 13, (ASM International, 2012).

12. Nielsen, P. S., Friis, K. S. \& Bay, N. Testing and modelling of new tribo-systems for industrial sheet forming of stainless steels. Proc. Inst. Mech. Eng. Part J J. Eng. Tribol. 225, 1036-1047 (2011). 
13. Omega. ANSI and IEC Color Codes for Thermocouples, Wires and Connectors. 1-7 Available at: http://www.omega.com/techref/colorcodes.html. (Accessed: 20th April 2017)

14. VANADIS 4-SuperClean TM. 1-9 Available at:

http://www.uddeholm.com.br/br/files/vanadis_4_english_04.pdf. (Accessed: 19th April 2017)

15. Lee, S., Nogami, M., Yamaguchi, S., Kurabuchi, T. \& Ohira, N. Evaluation of heat transfer coefficients in various air-conditioning modes by using thermal manikin. in 13th Conference of International Building Performance Simulation Association 2289-2296 (2013). 


\section{Figure Captions}

Fig. 1. Schematic of ironing process.

Fig. 2. Punch with the details of thermocouple holes shown by a) a schematic illustration and b) computed tomography (CT) scanning images of the actual punch.

Fig. 3. Schematic of experimental set-up.

Fig. 4. Representation of three dimensional discretization of the punch for thermal modelling with cross-sectional detail and indication of convection and radiation boundary conditions.

Fig. 5. Temperature evolution with time representing a) experimental results taken from thermocouples 1,2 and 3 ; b) numerical results taken from Thermocouple 1 and Thermocouple 2 positions for a specific heat transfer coefficient, $h=100 \mathrm{~W} /\left(\mathrm{m}^{2} \cdot \mathrm{K}\right)$; c) comparison of numerical results taken from Thermocouple position 2 using various heat transfer coefficient values with experimental findings.

Fig. 6. Temperature evolution with time taken from Thermocouple position 2 using various discretizations of the punch.

Fig. 7. Sensitivity analysis of measurement position shown by a) punch mesh and position of nodes and b) temperature evolution with time for the selected positions.

Fig. 8. Temperature evolution with time for two punch meshes and comparison with experimental results.

\section{Table Captions}

Table 1. CT scanning parameters.

Table 2. Experimental parameters.

Table 3. Input punch properties and process parameters used in numerical simulations. 